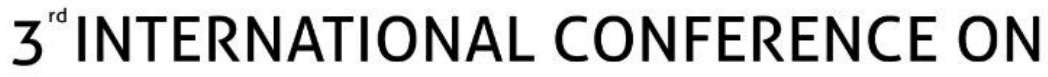 FUTURE OF TEACHING \& EDUCATION
}

\section{Perspectives on the Experience of Participating in English Language Presentation Contests}

\begin{abstract}
Dr. Richard Miles
Nanzan University, Japan

Abstract

Oral presentations are a commonly assessed task in university classes worldwide, particularly in ESP (English for Specific Purpose) and second language classes. As such, a substantial body of research exists, documenting the various facets of presentations skills and the views and experiences of both presenters and educators in the classroom. However, scant research exists on how such presenters perceive the experience of presenting outside the classroom, in contexts such as English language presentation contests. For motivated university students, presentation contests offer a further opportunity to experience presenting in a second language and a chance to pit themselves against top presenters from other universities. To better support students in preparing for the difficulties of presenting at such contests in a second language, their views and experiences need to be more rigorously investigated. Therefore, this study investigated the experiences of thirteen Japanese university students participating in three different English presentation contests. The primary research objective was to ascertain whether or not the presenters perceived their experiences as positive or negative, and to establish what factors had mitigated these views. A qualitative research design was employed, and data was collected through the administration of an online survey conducted after the contests had concluded. Thematic analysis and triangulation of the participants' responses indicates that most of the participants had positive experiences. Factors leading to this positive experience generally included either realizing specific pre-determined goals at the contest or being able to rationalize the holistic benefits of having competed in the contest.
\end{abstract}

Keywords: ESP, Learning experiences, Oral presentations

\section{Introduction}

Educators and researchers at the university level often proclaim that delivering oral presentations is a necessary and positive learning experience for students in the classroom, particularly for those studying English as a second language (Adams, 2004; Campbell et al, 2001; De Grez, et al., 2009; Pineda, 1999; Yang, 2010; Zappa-Hollman, 2007). While such studies have also shown that students tend to agree with this sentiment, few studies have explored whether university students also perceive participating in English language presentation contests as a positive experience. In the only known comparable study situated in the Japanese university context, Iimura (2016) discovered that implementing a presentation contest can reduce anxiety levels for English language learners. To address the gap in the literature relating to students' perspectives on presentation contests, this study investigates the

\section{info@icfte.com




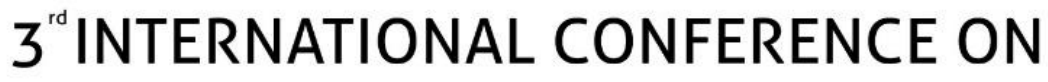 FUTURE OF TEACHING \& EDUCATION}

\section{Stockholm, Sweden}

\section{9-11 October 2020}

experiences of thirteen Japanese university students across three English presentation contests. The specific research objective is to ascertain whether or not the presenters perceived their experiences as positive or negative, and why.

\section{Background}

In the last decade, the Japanese Ministry of Education, Culture, Sports, Science and Technology (MEXT) has encouraged the implementation of "such educational forms as speeches [and] presentations" (Commission on the Development of Foreign Language Proficiency, 2011, p. 3) in the classroom, as a means of improving the overall communicative standards of spoken English in Japan. This clearly indicates that MEXT views presenting as a necessary and worthy experience for Japanese high school students, because the experience of presenting is seen as crucial for helping to develop and foster an increase in students' confidence for public speaking (Fujita, Yamagata, \& Takenaka, 2009). MEXT guidelines suggest that such experiences at the pre-tertiary level, will lead to improvements in Japanese students' presentation skill sets at the tertiary level (2014). Despite this initial push almost a decade ago, "Few studies have been conducted on English presentations in the Japanese English education context" (Fukawa, et al., 2018, p. 399).

Amongst studies that have been conducted in the Japanese context, findings typically reveal that presenting in English and speaking in front of other students is a great source of stress for Japanese university students (Burden, 2004; Ohata, 2005; Williams \& Andrade, 2008) and that it makes them feel shy and uncomfortable (Brooks \& Wilson, 2014). In addition, Kawachi (2012) found Japanese students viewed learning how to present in English as important, but that surprisingly few had presented at the university level, and even fewer had presented prior to entering university. For those that had experienced presenting in English in high school, they reported that instruction had typically focused on simpler elements, such as making eye contact, appropriate gesturing, and pronunciation (Eno, 2008). Few students believed that they had enough experience in high school learning about and using these skills to be able to successfully present on an academic topic (Apple, 2011).

Presentation contests offer Japanese university students an extra venue to practice and experience presenting in English. Yet, studies relating to English language presentation contests in Japan are rare. In one study on what differentiated successful and unsuccessful applicants to a contest, a review of the applicants' videos revealed that despite problems with some of the presenters" linguistics skills, "[unsuccessful] applications were more commonly let down by [a lack of] content, poor professionalism, and an inability to follow given instructions" (Fukawa, et al., 2018, p. 397), or by "not fully meeting or addressing the instructions of the chosen theme" (p. 404).

From the brief review of the literature noted in this section it can be deduced that both MEXT and Japanese students perceive English-language presentations as a worthy experience and one that is necessary. While much previous research has focused on exploring the views of educators and learners involved in the teaching, preparing, delivering, and reflecting on presentations, this research has largely been restricted to the university classroom context.

\section{Methodology}

\section{info@icfte.com}




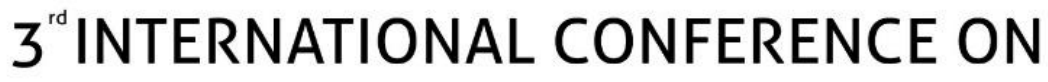 FUTURE OF TEACHING \& EDUCATION}

\section{Stockholm, Sweden}

\section{9-11 October 2020}

With a dearth of pre-existing studies on the experiences of Japanese students in English language presentation contests, the objective of this study is to simply explore such experiences. The core research question guiding this research is: Do the participants in this study perceive their experiences in an English language presentation contest as primarily a positive or negative experience? To help address this core question, two additional sub-research questions were formulated and serve to guide this study:

$>$ What are the participants' motives for entering English presentation contests?

$>$ Are the presenters' experiences shaped by their perceived success in the contest?

This study employs a qualitative research design with a framework encompassing three stages, outlined in Table 1.

Table 1: Research design

\begin{tabular}{|l|l|}
\hline Stage 1 & Ethics approval from the host institution was obtained (19-067). \\
\hline Stage 2 & $\begin{array}{l}\text { An online survey with thirteen presentation contestants was carried out. The survey was } \\
\text { comprised of prompts related to the sub-research questions. }\end{array}$ \\
\hline Stage 3 & $\begin{array}{l}\text { The data collected from Stage } 2 \text { were integrated and analyzed with an open coding } \\
\text { interpretive approach (see Charmaz, 2014) leading to thematic analysis (see Saldaña, } \\
\text { 2013), and grounded theorization (see Charmaz, 2014). }\end{array}$ \\
\hline
\end{tabular}

The participants were recruited through purposeful sampling (see Saldaña, 2013), and were drawn from a presentation contest circle at the university were the researcher was situated. All of the members participating in the 2019 contests were given the option of volunteering to be involved in the research or to abstain. Those choosing to volunteer were first given an explanation of the research, and then asked to sign consent forms and to then anonymously complete the survey online after the contests. A self-administered online survey - now the primary means or conducting surveys (Fink, 2017; Evans \& Mathur, 2018) - was chosen as they are faster and more convenient for participants (Minnaar \& Heystek, 2013; Nosen \& Woody, 2008; Wiersma, 2013) and allow for privacy. This helped to minimize the risk of investigator bias (see Yin, 2014) as the researcher and the participants were familiar with each other and to eliminate interviewer effects (see Wiersma, 2013), whereby the participants feel pressured to respond in certain ways that they believe are desired by the interviewer when responding face-to-face. Due to the small number of participants, typical online survey issues such as invalid participation and multiple participation (Nosen \& woody, 2008), were not problematic. The online survey was conducted with the participants approximately one month after the contests and the response rate was $100 \%$. A breakdown of the background of the thirteen participants' is outlined in Table 2.

Table 2: Participants' background information

\begin{tabular}{|l|l|l|}
\hline Gender & Female (12 participants) & Male (1 participant) \\
\hline Nationality & Japanese $(10$ participants $)$ & Other (3 participants) \\
\hline Year of study & $1^{\text {st }}$ year (4 participants) & $2^{\text {nd }}$ year $(6$ participants $)$ \\
\hline & $3^{\text {rd }}$ year $(2$ participants $)$ & $4^{\text {th }}$ year $(1$ participant $)$ \\
\hline English class placement & Advanced level $(3$ participants $)$ & Regular level (10 participants) \\
\hline
\end{tabular}




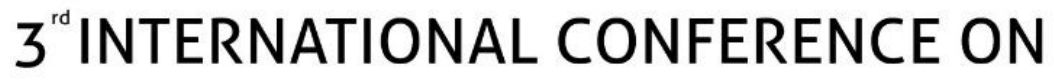 FUTURE OF TEACHING \& EDUCATION}

\section{Stockholm, Sweden}

\section{9-11 October 2020}

The participants' age was not solicited but it can be estimated that they ranged from 18-25. The participants all completed the survey, consisting of eight questions, over a period of two weeks, approximately one month after competing in an English presentation contest. Their responses were all in English and were collected via the SurveyMonkey platform. The participants were not paid for their participation. The questions and prompts posed to the participants are detailed in Table 3.

Table 3: Online survey questions/prompts

\begin{tabular}{|l|l|}
\hline Question 1 & Why did you enter the presentation contest? \\
\hline Question 2 & What was your goal before going to the contest (if you had one)? \\
\hline Question 3 & $\begin{array}{l}\text { Rate your experience at the contest: (Extremely positive/ Positive/Mixed/A little } \\
\text { disappointing/Very disappointing) }\end{array}$ \\
\hline Question 4 & When you reflect on this experience now, how do you feel? \\
\hline Question 5 & What did you do well in your presentation? \\
\hline Question 6 & What did you need to do better? \\
\hline Question 7 & How did the experience compare to your expectations before going? \\
\hline Question 8 & $\begin{array}{l}\text { If you are to enter the contest again next year, what kind of support would you like } \\
\text { more of? }\end{array}$ \\
\hline
\end{tabular}

With the exception of Question 3, all of the questions were open-ended questions and participants were free to respond in as much detail as they wished. For Question 3, the participants were required to select from one of the five options given (see Table 3). The participants were also able to skip questions they did not wish to answer. The length of the responses varied according to the participant and according to the question, with some responses consisting of a single word, while others consisted of a paragraph answer. All the responses were given in English.

The participants presented individually (six participants), or in groups (two pairs and one group of three) at three different contests around Japan. Amongst the participants, there were varied levels of success. Two individual presenters were winners of their respective contests, several others placed highly in their contests, while several other participants did not place near the top.

When analyzing the data, the participants were assigned a number, based on their order of response, to help cross reference responses in the data. For example, the first participant who responded to the online survey is referred to as P1 in the Results and Discussion section. To analyze the data obtained in the survey, an open coding interpretive approach (see Charmaz, 2014) leading to thematic analysis (see Saldaña, 2013), and then grounded theorization (see Charmaz, 2014) were used for addressing the core research question and the two sub-research questions.

\section{Results and discussion}

The first important finding comes from examining the participants' responses to Question 3, which addresses the core research question in this study (Do the participants in this study perceive their experiences in an English language presentation contest as primarily a positive or negative experience?). Table 4 provides a breakdown of the participants' responses.

\section{info@icfte.com_www.icfte.com}




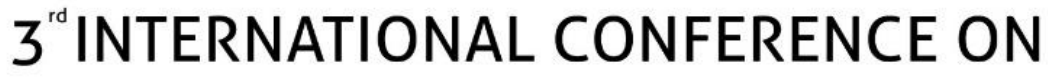 FUTURE OF TEACHING \& EDUCATION}

\section{Stockholm, Sweden}

9-11 October 2020

\begin{tabular}{|l|c|l|}
\hline Response option & Number of participants & Participants \\
\hline Extremely positive & 5 & P3, P7, P8, P10, P11 \\
\hline Positive & 6 & P1, P2, P5, P9, P12, P13 \\
\hline Mixed & 1 & P4 \\
\hline A little disappointing & 1 & P6 \\
\hline Very disappointing & 0 & \\
\hline
\end{tabular}

As can be clearly seen in Table 4, the overwhelming majority of participants rated their experience as either "Extremely positive" or "Positive". Only one selected "Mixed" and one selected "A little disappointing". None of the participants selected "Very disappointing". This would indicate that most of the participants viewed their experience of presenting at the contests as a positive experience.

To better understand the rationale behind their views, it is necessary to explore their responses to the seven open-ended questions and prompts in the survey. An open coding interpretive approach (see Charmaz, 2014) for thematically analyzing the answers was applied to the raw data. This meant that responses with similar content were given the same coding tag, following the principle of similarity. An example of this is the coding tag, "to win". Any response where the participant indicated their motivation for entering the contest was to win the contest or win a prize was given this coding tag. The data were coded through a recursive process - as recommended by Yin (2014) to better ensure intra-rater reliability. Then, an inductive approach (see Yin, 2014) was utilized to formulate theories addressing the research questions.

Firstly, to better understand why the participants almost all had positive experiences presenting at a contest, it is necessary to understand the motivation behind the participants' decision to enter the contest (one of the two sub-research questions). When responding to Question 1 (Why did you enter the presentation contest?), the participants largely answered in idealistic terms. The desire to 'try something new' was stated by three participants (P1, P11, P13) and an interest in 'checking their English skill level' (P5, P7, P9, P10, P11) and 'checking their presentation skills' (P4) were common answers given by many participants. Several other participants mentioned 'the presentation contest themes' (P5, P12, P13) and 'the experience of presenting on the big stage' (P6) as underlying reasons for entering the contests. Only P2 mentioned the specific objective of 'promoting a certain product' in the presentation as being the reason for entering. It would seem then, that verifying presentation and language skill sets, tackling a new challenge, and an interest in the experience or themes of the contest were the prominent motivating factors behind the participants entering the contests.

When asked about their goal prior to entering the contest (Question 2), the participants were far more specific with their responses, which often related to a certain placing at the contest. Most wanted to place in 'the top five or ten' of the contests (P2, P4, P6, P8, P10, P12), 'to win the contest' (P1, P6, P9, P11, P13), or to simply just be 'selected to compete in the contests' (P3). Only a few holistic responses were initially offered, such as, "to make a powerful speech" (P7), to "broaden my horizons" (P11), "to brush up my skills' (P5), and 'to make the best of the experience and meet new people' (P13). 


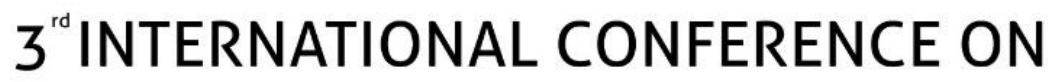 FUTURE OF TEACHING \& EDUCATION}

\section{Stockholm, Sweden}

\section{9-11 October 2020}

The combined responses for Questions 1 and 2 suggest that while many participants were initially attracted by the desire to test their English and presentation skills, or by the topics at the contest, they were also particularly motivated to obtain some kind of verification of this by winning the contest, or by placing near the top. Considering these annual contests are very competitive and demanding, one might expect that the participants were initially setting themselves up for disappointment and therefore, a more negative experience.

For the next two questions, the participants were asked about what they considered to have been the strengths and weaknesses of their presentations (Question 5 and 6). Their responses reveal interesting insights into a wide range of external and internal factors contributing to the success and failure of their presentations. Positively evaluated factors included 'delivery skills' (P1, P3, P9, P10, P12, P13), 'overall clarity of the presentation' (P3, P5, P6, P12), 'coming up with good ideas' (P8), good 'background research' (P11), 'being able to introduce a new product' (P2), having 'good visuals' (P4), and, in the case of one very confident participant, "All" (P7). Almost all of these factors have one thing common; they can be prepared before the presentation and practiced. Given that the participants willingly entered the contest of their own free will, it can be speculated that they were all at least somewhat strongly motivated to achieve specific results. Therefore, the likelihood that they had prepared and practiced well, and then delivered certain components of their presentation well, is not entirely surprising. Only P4 thought they had succeeded in the most notoriously difficult element of a presentation contest, the question and answer session - something that cannot really be prepared in advance.

In terms of the self-assessed weak points of their presentations, several participants indicated the 'Q \& A sessions' (P2, P10) had been difficult, while the most frequent response related to a regret over having 'not practiced or prepared sufficiently' (P3, P7, P11). Perceived failures relating to delivery of the presentation were also relatively prominent, with the participants citing the 'need for more body language' (P1), to have exhibited 'more confidence' (P13), to have 'spoken more slowly' (P6), 'more clearly' (P8), and in a 'more interesting way' (P12). P4 also added that having known more about "what the judges wanted and what their bias was" would have been beneficial, and also betrayed a certain sense of dissatisfaction with the outcome of the contest (P4 had rated the experience as "mixed" - the second lowest of the participants).

The participants noted many different factors relating to the self-perceived strengths and weaknesses in their presentations. From these findings it is difficult to accurately draw any specific conclusions other than a range of factors were perceived to have either enhanced the participants' presentations or to have undermined them.

For Question 8, the participants were asked about the possibility of entering contests again in the future and what kind of support they required. The participants largely either noted the need for more practice, advice and critical comments during and after the practice sessions ( $\mathrm{P} 2, \mathrm{P} 4$, P6, P10, P11, P13) or the need for more financial support to travel out of town for the contests (P4, P9, P12, P13). Only P1 commented that they would need to make their presentation more exciting and humorous next time. P3 skipped the question and three others simply replied that they were satisfied with the support they received on this occasion (P5, P7, P8). 


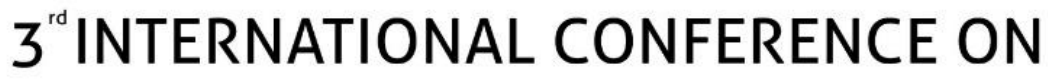 FUTURE OF TEACHING \& EDUCATION}

\section{Stockholm, Sweden}

\section{9-11 October 2020}

In the next stage of the analysis, the individual participant responses (to Question 4 and 7) are synthesized to obtain a better look at the potential rationale for the findings to the core research question of the study discussed above. Questions 4 and 7 asked the participants to reflect on their experiences and to compare it with their expectations before the contest. Of note, one participant skipped both questions 4 and 7 (P9). It is not known why this participant skipped both questions. They rated their experience as "positive", so it is considered unlikely that any negative experiences led them to avoid answering this question.

Firstly, the participants who rated their experience as "extremely positive" were P3, P7, P8, P10, and P11. From the same open coding procedures employed to analyze the earlier data, three themes seem to best encapsulate the rationale behind the participants ratings: 'learned a lot' (P8, P10, P11), 'better than expected' (P3, P8, P11) and 'achieved their goal' (P3, P7, P8, P10).

P3 responded, "I felt I achieved my goals because we practiced again and again. It was better than I expected." P3's original goal was just to make it to the final, which was accomplished, meaning it was not so surprising that this participant rated their experience as "extremely positive". P3 believed extensive practice and good content had helped achieve this goal and merely thought more practice would have made it better. This could be indicative of little selfreflection, or a general satisfaction with how the experience had gone.

P7 also rated the experience as "extremely positive", which is not overtly surprising, given that this participant won the contest they entered. Upon reflecting, P7 noted that, "I think I did my best" and that everything had worked well. Given that the participant's initial goal was to merely practice English and to make a powerful speech, it can be said this participant matched and even exceeded their goal for the experience.

P8 illustrates a different type of finding as this participant's initial goal was to place "in the top 5", but who failed to achieve this objective. Nevertheless, P8 still rated the experience as "extremely positive" and thought the experience had been better "than I expected" because of the many positive learning outcomes obtained. These outcomes were explained in greater detail than by other participants and included the experience of presenting "in front of many strangers", gaining "more confidence with my English and presentation skills", having the opportunity to "watch another participant's presentations", and learning "different opinions from ours". Clearly, placing in the top 5 might have been the initial objective, but P8 still had a positive experience for a variety of other more holistic reasons.

P10 won an award at the contest and unsurprisingly rated the experience as "extremely positive". The initial goal had been to "get an award", which was clearly met. P10 had also indicated a desire to "know my English skill", and then felt "positive, because I could know my English skill" through the experience, indicating the contest had validated P10's English skills. P10 also noted, "it was so great because I could watch senior students' good speeches".

P11 was the other participant who rated their experience as "extremely positive". This participant had two initial goals; "I would have liked to get a prize. But, also, I wanted to broaden my horizon". Although this participant did not win any prizes, they still felt "it was a

\section{info@icfte.com www.icfte.com}




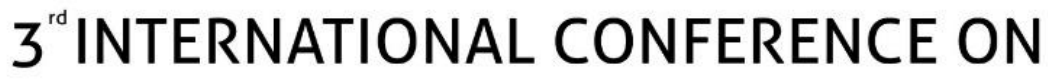 FUTURE OF TEACHING \& EDUCATION}

\section{Stockholm, Sweden}

\section{9-11 October 2020}

very satisfying experience... I could interact with many people and tell my presentation clearly". Clearly the participant felt they had achieved their second goal.

From these five cases it can be surmised that there are two keys to having an "extremely positive" experience at an English presentation contest. The first is rather obvious and relates to two participants (P7 \& P10) who won prizes. Naturally, this leads to positive experiences for presenters. The other three participants did not win any prizes but either received validation of their English language and presentation skills by being chosen to present at the final round or were able to realize more holistic goals from participating in the contest and furthering their knowledge and experiences.

Next, the participants who rated their experience as "positive" were P1, P2, P5, P9, P12, and P13. None of these participants won any awards but were generally satisfied with their overall experience. As with the participants who rated their experience as "extremely positive", this group of participants also seemed to have met specific goals or holistic goals, and therefore rated the experience as "positive".

P1 had initially set goals of wanting "to try something new" and to "get any prize" but was still ultimately satisfied "because I practiced hard and prepared well". P1 was also surprised "that I wasn't as nervous as expected". The first goal was obviously met just by participating in the contest and the positive feelings of not being so nervous contributed to an overall sense of positivity about the experience, despite not getting a prize.

P2 initially wanted "to get on the podium" but also wanted "to introduce a Vietnamese product", reflecting two distinct original goals. While failing to get on the podium, P2 was still satisfied "because I completed my goal", presumably the second goal of making "other people know about an underrated product from my country". The experience was still "better than I expected". As with P1, the failure to win the contest was less of an issue because the participant's other goal had been met.

P5 also felt the experience had been "positive". This participant had several distinct goals prior to the experience, including verifying that their English skills had improved over the duration of their university studies, learning more about the specific content of the presentation, and to also improve their presentation skills. Although this participant did not place highly in the contest, they were satisfied with many holistic experiences at the contest, such as, the "great experience to express my thoughts and ideas to many people" and "I became more confident to speak in front of people... and to have more interests in many fields". Although the holistic goals at the outset had been hard to verify, the participant was still able to draw on a range of other positive holistic experiences.

P12 was initially "interested in this contest [theme]" and set the goal of going "to the final". This second goal was met, and the participant was "satisfied because we did our best and I could learn and think about many things related to the topic". Although the participant was disappointed not to place near the top, a realistic view on things: "everyone who gave a presentation was wonderful and I could learn many things", was offered to justify their position that the experience was still positive.

\section{info@icfte.com}




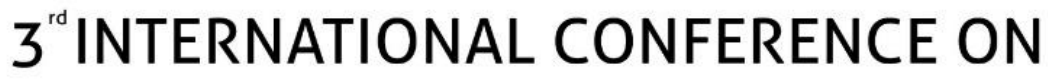 FUTURE OF TEACHING \& EDUCATION}

\section{Stockholm, Sweden}

\section{9-11 October 2020}

P13 was the last participant to rate their experience as "positive". Like P1, this participant wanted to 'try something new', and like other participants, was simply interested in the contest themes. P13 had a complex array of goals, such as, "making the best use of this experience, having fun, meeting new people, and hopefully getting a reward". As with some other participants who did not get any award or prize, P13 elaborated on the initial disappointment of not getting an award, "Right afterwards I was disappointed in my presentation skills and my English skills, but it is great motivation for me to improve. It was as great as I expected and I learned a lot from other presenters", and noted in the end, "I am feeling very positive after all." As with many other participants in this group, holistic goals being met seemed to outweigh any potential failure to win an award.

As with the participants who rated their experience as "extremely positive", the participants who rated their experience as "positive" had a similar rationale, based on either meeting specific objectives such as getting to the final round of the contest, or on gaining more holistic learning experiences.

Finally, two participants were not overly positive in rating their experience. P4 rated the experience as "mixed" and P6 rated it as "a little disappointing". P4 stated "I love to present and I would like to assess how well I can do it", and targeted "the top 10" initially as a specific goal. As with many other presenters, this specific goal was not met, but unlike other participants, P4 did not seem to believe the more holistic goals of experiencing the contest had been met. P4 stated, "I didn't achieve my goal of reaching the top 10. I was disappointed with myself. However, when I saw the finalists, I thought I would not make a presentation like that. They are not bad presentations, but just very different from what I consider a good presentation." $\mathrm{P} 4$ did note a few holistic positive experiences, similar to other participants, such as, "I learned a lot from other presenters". Interestingly, P4 also commented that in future, participants should "research what the judges wanted or their bias", indicating a certain degree of external dissatisfaction with how the contest had been judged.

P6 seemed to have had the least positive experience of the thirteen participants in this study and rated their experience as "a little disappointing". P6's initial goals were similar to the other participants, "for the experience" and "I wanted to at least get into the top 10". Failing to meet the second objective was attributed to external factors (as P4 had done), "the competition seemed to be based somewhat on luck. The contents didn't seem to matter as long as you presented well". P6 later mentioned the same external factor (luck) in explaining their lack of success, "I didn't have the presentation that was needed for the win but felt like luck was needed in order to get in the top $10 "$ ".

When comparing the two participants who were less positive in their reflections of the experience with those who were more positive, several explanations can be seen in the findings. Firstly, most of the participants had similar initial specific goals, such as, placing highly in the contest, winning it, or just getting to the final. Many participants also had more holistic goals, such as validating their English language and presentation skill sets. The other commonly cited goal was a more general goal of just experiencing the contest. While two participants won awards, the other eleven did not. Nevertheless, the vast majority of the participants evaluated the experience as positive, and justified their rating based on more holistic reasons. The key difference between these participants and the two more negative participants, is that the latter 


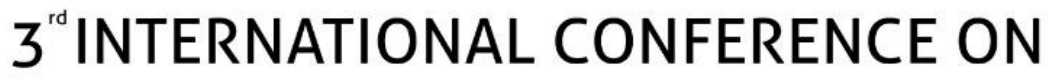 FUTURE OF TEACHING \& EDUCATION}

\section{Stockholm, Sweden}

\section{9-11 October 2020}

did not really seem to feel that the holistic benefits obtained from presenting in a contest had been obtained, and also indicated they believed that external factors (biased judges or luck) had played a part in their failure to place more highly.

\section{Implications and limitations}

There are several important implications for educators and researchers that can be drawn from this small study. Firstly, it would appear that presenting in English (as an L2) at a presentation contest can be a positive experience, and indeed was a very positive experience for many of the participants in this study, despite the obvious stress and anxiety that public speaking can induce amongst students. This means that as educators, we should be encouraging our students to participate in these contests and emphasizing to them the beneficial experiences that can be gained from participating in such contests.

Secondly, the reason it can be a positive experience for participants appears largely to be based on achieving specific goals established before the contest, or from perceived holistic takeaways after the contest. This is important to consider as those students who do participate in presentation contest will need support from educators. Such support should feature making students more aware of how having specific goals before the contest is important, but that also having holistic goals can help mitigate against any negative experiences such as failing to meet specific goals.

Finally, there are a few limitations to this study that should be noted. Firstly, the number of participants is small, so further work needs to be done in this area. Secondly, this study included only participants who were selected to attend the contests, and did not include those who had applied, but who had not been selected. Obviously, they could not be included as they did not actually present at the contest, but their experiences should be explored in the future as their likely contrasting experiences could offer important insight into the greater experience of applying for presentation contests and then being accepted or being rejected. Finally, it should also be noted that the participants in this study all come from a university with a wellestablished reputation for English language education and a good track record at these presentation contests. For a more robust view of the experiences of participants at presentation contests, it would be prudent to include participants from different universities, especially those from universities with less-established English language programs and with less support from instructors.

\section{Conclusion}

The core question in this study sought to establish if Japanese university students participating in English language presentation contests viewed their experiences as positive or negative. The answer to this question was clearly 'positive'. Thirteen of the fifteen participants in this study rated their experience as 'positive' or 'extremely positive'. One participant rated it as 'mixed', while one other participant rated it as 'a little disappointing'. The qualitative findings from this study further indicate that participants who either met specific goals (such as winning the contest), or who felt they had achieved more holistic goals (such as learning from other presenters, gaining verification of their English language or presentation skills, or gaining confidence from the experience), rated the experience of presenting at a contest as 'extremely positive' or 'positive'. The two less positive participants tended to attribute their perceived lack

\section{info@icfte.com}

www.icfte.com 


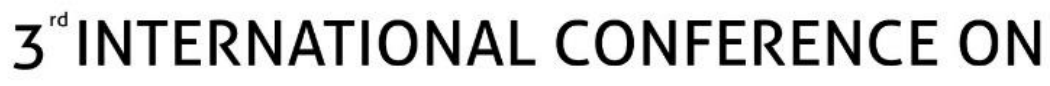 FUTURE OF TEACHING \& EDUCATION}

\section{Stockholm, Sweden}

\section{9-11 October 2020}

of success to external factors outside their control (luck and biased judges) and therefore, perceived the experience as less positive than the other participants. Being able to extrapolate the findings from a small study such as this is difficult, but the study can serve as a basis for future research, determining how participants in English language presentation contests perceive their experiences.

\section{Acknowledgment}

This study was conducted with the support of a Nanzan University Pache Research Subsidy (1A-2) for the 2020 academic year.

\section{References}

Adams, K. (2004). Modeling success: Enhancing international postgraduate research students' self-efficacy for research seminar presentations. Higher Education Research \& Development, 23(2), 115-130.

Apple, M. (2011). The big five personality traits and foreign language speaking confidence among Japanese EFL students (Doctoral dissertation). Kyoto: Ritsumeikan University.

Brooks, G., \& Wilson, J. (2014). Using oral presentations to improve students' English language skills. Kwansei Gakuin University Humanities Review, 19, 199-212.

Burden, P. (2004). The teacher as facilitator: Reducing anxiety in the EFL university classroom. JALT Hokkaido Journal, 8(1), 3-18.

Campbell, K.S., Mothersbaugh, D.L., Brammer, C., \& Taylor, T. (2001). Peer versus selfassessment of oral business presentation performance. Business Communication Quarterly, 64(3), 23-42.

Charmaz, K. (2014). Constructing Grounded Theory. Los Angeles: Sage.

Commission on the Development of Foreign Language Policy. (2011). Five proposals and specific measures for developing proficiency in English for international communication. Retrieved from http://www.mext.go.jp/component/english/_icsFiles/afieldfile/2012/07/ 09/13197071.pdf

De Grez, L., Valcke, M., \& Roozen, I. (2009). The impact of an innovative instructional intervention on the acquisition of oral presentation skills in higher education. Computers \& Education, 53, 112-120.

Eno, K. (2008). Transforming reticent students to oral presenters. JALT2007 Conference Proceedings, 653-667.

Evans, J.R., \& Mathur, A. (2018). The value of online surveys: A look back and a look ahead. Internet Research, 28(4), 854-887.

Fink, A. (2017). How to Conduct Surveys: A Step-by-step Guide. Los Angeles: Sage.

Fujita, R., Yamagata, A., \& Takenaka, K. (2009). Gakusei no ishikihenka ni miru eigo presentation jugyo no yuyosei [Effectiveness of an English presentation course, as seen in changing student attitudes]. Tokyo Keizai Daigaku Jinbun Shizenkagakuronshu, 128, 3553.

Fukawa, T., Faulhaber, D., Lloyd-Williams, A., \& Morris, S. (2018). Success in national presentation contests. The Journal of Kanda University of International Studies, 30, 397413.

Iimura, H. (2016). The effect of an oral presentation contest on students' anxiety in Japanese EFL context. KATE Journal, 30, 71-84.

\section{info@icfte.com}




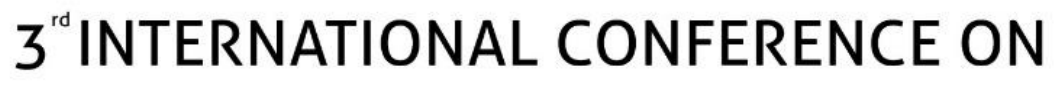 FUTURE OF TEACHING \& EDUCATION}

\section{Stockholm, Sweden}

\section{9-11 October 2020}

Kawachi, T. (2012). The importance of incorporating student presentations in ELF listening courses. Bulletin of Seikei University, 46(4), 1-19.

MEXT. (2014). English education reform plan corresponding to globalization. Retrieved From http://www.mext.go.jp/en/news/topics/detail_icsFiles/afieldfile/2014/01/23/ 1343591_1.pdf

Minnaar, L., \& Heystek, J. (2013). Online surveys as data collection instruments in education research: A feasible option? South African Journal of Higher Education, 27(1), 162-183.

Nosen, E., \& Woody, S.R. (2008). Online Surveys: Effect of research design decisions on rates of invalid participation and data credibility. Graduate Student Journal of Psychology, 2008(10), 3-14.

Ohata, K. (2005). Potential sources of anxiety for Japanese learners of English: Preliminary case interviews with five Japanese college students in the U.S. TESL-EJ, 9(3), 1-21.

Pineda, R. C. (1999). Poster sessions: Enhancing interactive learning during student presentations. Journal of Management Education, 23, 618-622.

Saldaña, J. (2013). The Coding Manual for Qualitative Researchers (2 ${ }^{\text {nd }}$ ed.). London: Sage.

Wiersma, W. (2013). The validity of surveys: Online and offline. Oxford Internet Institute, 18(3), 321-340.

Williams, K. E., \& Andrade, M. R. (2008). Foreign language learning anxiety in Japanese EFL university classes: Causes, coping and locus of control. Electronic Journal of Foreign Language Teaching, 5(2), 181-191.

Yang, L. (2010). Doing a group presentation: Negotiations and challenges experienced by five Chinese ESL students of commerce at a Canadian university. Language Teaching Research, 14(2), 141-160.

Yin, R.K. (2014). Case study research: Design and methods. Thousand Oaks: Sage.

Zappa-Hollman, S. (2007). Academic presentations across post-secondary contexts: The discourse socialization of non-native English speakers. The Canadian Modern Language Review / La Revue Canadienne de Languages Vivantes, 63(4), 455-485. 